\title{
Job strain and symptoms of angina pectoris among British and Finnish middle-
}

aged employees

Running title: Job strain and angina pectoris

Revision \#3 to the Journal of Epidemiology and Community Health

Tea Lallukka ${ }^{1}, \mathrm{PhD}$; Tarani Chandola ${ }^{2}, \mathrm{PhD}$; Harry Hemingway ${ }^{2}, \mathrm{PhD}$; Professor Sir

Michael Marmot ${ }^{2}, \mathrm{PhD}$; Professor Eero Lahelma ${ }^{1}, \mathrm{PhD}$; Ossi Rahkonen ${ }^{1}, \mathrm{PhD}$

${ }^{1}$ Department of Public Health, University of Helsinki, Finland

${ }^{2}$ Department of Epidemiology \& Public Health, University College London, UK

\section{Competing Interest: None declared.}

Word counts: Main text (3168), Abstract (203) Tables (2)

Key words: angina pectoris symptoms; job strain; international comparison

"The Corresponding Author has the right to grant on behalf of all authors and does grant on behalf of all authors, an exclusive licence (or non exclusive for government employees) on a worldwide basis to the BMJ Publishing Group Ltd and its Licensees to permit this article (if accepted) to be published in JECH editions and any other BMJPGL products to exploit all subsidiary rights, as set out in our licence (http://jech.bmj.com/ifora/licence.pdf)".

Correspondence:

Tea Lallukka, PhD, MSc (Nutrition)

Department of Public Health

P.O.Box 41 (Mannerheimintie 172)

00014 University of Helsinki, Finland

Tel: +358919127566

Fax: +358919127540

E-mail: tea.lallukka@helsinki.fi 


\section{ABSTRACT}

Background: High job strain has been linked with cardiovascular outcomes. This study aimed to examine whether job strain is associated with angina pectoris symptoms among British and Finnish non-manual employees.

Methods: Postal questionnaire survey data among 40 to 60 year-old employees of the British Whitehall II Study ( $n=4551,27 \%$ women) and the Finnish Helsinki Health Study ( $\mathrm{n}=7605,83 \%$ women) cohort were analyzed. Angina pectoris symptoms were the outcome in logistic regression analysis. Karasek's job strain was examined. Models were adjusted first for age, secondly for occupational class, and finally for smoking, heavy drinking, physical inactivity, unhealthy food habits, and obesity.

Results: Angina pectoris symptoms were reported by $5 \%$ of women and $3 \%$ of men in Britain, and by $6 \%$ of women and $4 \%$ of men in Finland. High job strain was associated with angina pectoris symptoms among men in Britain (OR 2.08; CI 95\% 1.07-4.02) and women in Finland (OR 1.90; CI 95\% 1.36-2.63) independent of age, occupational class, and behavioral risk factors. However, similar associations between job strain and angina pectoris symptoms were not observed among men in Finland or women in Britain.

Conclusion: The results yielded partial support for the association between job strain and angina pectoris symptoms across national contexts. 


\section{INTRODUCTION}

Angina pectoris is a manifestation of coronary heart disease with chest pain experienced upon exertion. Angina prevalence has been estimated to be higher than what is clinically identified, with the prognosis of undiagnosed population being similar to those with diagnosed disease.[1,2] Furthermore, although myocardial infarction is twice as common among men than women, register-based analyses about nitrate use suggest that angina among women is common.[1] Angina pectoris symptoms are also less benign than often assumed as coronary mortality is elevated among women with nitrate prescriptions.[3] While self-reported prevalence of angina pectoris symptoms is higher for women [4], men still receive more treatment.[1] Therefore, more evidence is needed to better understand and identify angina pectoris symptoms also among women.

The contribution of job strain, i.e., combination of high job demands and low job control [5], to both coronary morbidity [6-14] and mortality [15-17] is supported by many studies. Chronic job strain is also associated with an increased risk of recurrent coronary heart disease events, both fatal and nonfatal.[18] However, some studies have failed to find an association between job strain and coronary health, or suggested that it might be spurious $[19,20]$, and further work is warranted to clarify the associations. These associations between work stress and coronary heart disease tend to be weaker among women as compared to men [21]. However, there are few studies looking at work stress and angina pectoris symptoms among women and men separately. It could be hypothesized that as women report more angina pectoris symptoms than men [4], the association between work stress and angina pectoris symptoms would also be stronger among women than men. 
Health behaviors, obesity, as well as sociodemographic and socioeconomic factors, alongside working conditions are potentially related to job strain and angina pectoris symptoms. Thus, these factors need to be considered in further analyses to show more robust effects between working condition and health outcomes. First, job strain shows some associations with behavioral coronary risk factors [22,23], which may refer to indirect effects of job strain on coronary heart disease. Secondly, socioeconomic position and working conditions are intertwined, i.e., job strain may interact with socioeconomic position.[24] Although not consistently, high job strain has been more common among those in lowest socioeconomic positions, with the poorest health observed among those with both low position and high job strain.[24] Thirdly, all of the potential confounders are associated with coronary heart disease morbidity and mortality.[17,25,26] angina pectoris symptoms are also associated with an adverse risk factor profile even among younger women.[27]

Previous international comparisons on angina pectoris symptoms and job strain are non-existent. Additionally, gender differences in angina are not yet sufficiently understood. Therefore, we sought to add the current understanding on the associations between psychosocial job strain and angina pectoris symptoms among women and men by examining employee cohorts from Britain and Finland. The rationale for the international comparison is to add generalizability of the results, assess whether the associations are common across occupational cohorts as well as add the external validity. More specifically, the study design is stronger when framework of this study can be tested in two settings assessing whether the associations are similar or differ between cohorts.

The aims of this study were as follows: 1) to examine the associations between job strain and angina pectoris symptoms, 2) to examine the effects of potential 
confounding factors, i.e., age, occupational class, and behavioral risk factors on the studied associations, and 3) to compare the studied associations in two national contexts as well as between women and men.

\section{METHODS}

\section{Data}

We used cross-sectional survey data from British and Finnish public sector employee cohorts. The data collection in the Finnish Helsinki Health Study largely followed the protocol of the British Whitehall II study (London). In both countries, the employees were contacted at their work-place by sending a postal questionnaire. The University College London ethics committee approved the Whitehall II study, and Helsinki Health Study has had ethical approvals by the Department of Public Health, University of Helsinki as well as City of Helsinki.

The Whitehall II (WHII) study is a cohort of 10308 female and male white-collar employees of 20 civil service departments in London, UK, at baseline (1985-1988). [28] Initial response rate was $73 \%$. For the purposes of this study, questionnaire data from phase 5 collected in 1997-1999 ( $\mathrm{n}=7830)$ were examined. We included all participants who were still employed in phase 5 and who were aged 45-60 years $(\mathrm{n}=4551$, women $27 \%)$.

Baseline postal questionnaire data for the Helsinki Health Study (HHS) were collected in 2000-2002 among middle-aged employees of the City of Helsinki, Finland ( $\mathrm{n}=8960$, response rate 67\%) [29]. For comparisons, white-collar employees aged 40-60 years were included $(n=7605$, women $83 \%)$. 


\section{Measures}

Angina pectoris symptoms

The Rose Questionnaire [30] was developed as a standardized instrument for assessing the prevalence of angina pectoris symptoms. Angina pectoris symptoms are elicited by a series of questions that need to be responded according to specific criteria.[31] First, participants are enquired about whether they ever have experienced any chest pain or discomfort. Exertional chest pain is experienced while hurrying (grade 1) or walking on the level (grade 2), with pain forcing the activity to be stopped or slowed down. After cessation of effort, pain should be relieved within 10 minutes. Pain should be situated over the sternum or in the left anterior chest and left arm. All of the original Rose questionnaire items [30] are hurdles which must be cleared before becoming an angina case. A participant is classified as not having angina pectoris symptoms, if the first item on ever having chest pain is 'No', or if the first item is 'Yes' and the second item on exertional chest pain is 'No', or if the first item is 'Yes' and the second item is 'Yes' but the items 4-7 enquiring about the duration of the chest pain, its location etc., are not fulfilled. More details and the complete questionnaire can be found in a previous report.[32]

\section{Psychosocial work environment}

Psychosocial job strain was examined using Karasek's job strain model. According to this model $[5,14]$, low strain is characterized by a combination of low job demands and high job control, whereas high strain refers to a combination of high job demands and low job control to surmount the perceived demands. Additionally, active work with good motivation and learning opportunities is the combination of high job demands and control, whereas passive work combines low job demands and low job 
control. High strain exposes to excessive work stress which is expected to have detrimental health effects including risk of cardiovascular diseases.[6]

Four similar items on job demands and eight items on job control in both cohorts were included.[22] The items were summed up and the median in the distribution of the sum score was used as a cut-off point for high job demands and high job control, separately by cohort and gender. The Cronbach's alpha for the job demand dimension was 0.7 and for the job control dimension 0.8 in both cohorts and among women and men.

\section{Behavioral risk factors}

Four key health behaviors and obesity were included and adjusted for as behavioral risk factors. Smoking was dichotomized as current smoking of cigarettes, cigars or pipes, and non-smoking. Heavy drinking was measured by consuming more than 280 grams of pure alcohol per week for men and 140 grams per week for women. The alcoholic content of each reported drink during the previous week (London) or average weekly consumption (Helsinki) was multiplied by the number of standard units consumed. The physically inactive group in London comprised those reporting one hour or less of mild, moderate, and vigorous leisure time physical activity per week. In Helsinki, the lowest quintile of the sum of mild, moderate, and vigorous physical activity reflected a similar proportion of physical inactivity as in London. Healthy food habits were measured by consuming fruit and vegetables at least twice a day, and choosing wholegrain bread and low-fat milk as typical choices in place of white bread and whole milk. Those reporting no such healthy food habits were classified as having unhealthy food habits. Obesity was measured by body mass index (BMI) of at least 30. BMI was based on measured height and weight in London 
(weight/height*height) and self-reported height and weight in Helsinki. Self-reported measures somewhat under-report obesity.[33]

\section{Covariates}

Age was a covariate in all the models.[34,35] In both cohorts, socio-economic position (SEP) was measured by current occupational social class. Following our previous comparative studies $[22,36]$, three hierarchical white-collar classes were used as shown in Table 1.

\section{Missing values}

All those not fulfilling all of the original criteria [30] were defined as not having angina pectoris symptoms. Angina pectoris symptoms are missing if the first item requesting about ever having pain is missing, or if the first item is 'Yes' and the second item on exertional chest pain is missing.

For those missing one item out of four items for job demands or two items out of eight for job control at the most, missing values were included in the analyses and replaced by mode to avoid unnecessary loss of data in the multivariate analyses. This method was applied to 1-3\% of participants only.

\section{Statistical methods}

We first computed percent distributions of angina pectoris symptoms, job strain, and covariates in the London and Helsinki cohort (Table 1). Logistic regression analysis was used to examine the associations between angina pectoris symptoms and job strain. Model 1 shows the age-adjusted individual effects of job strain, whereas in Model 2 also occupational class is adjusted for. Finally, in Model 3, behavioral risk 
factors and obesity are adjusted for. Multivariate models were all fitted within the pooled dataset stratified by cohort and gender in order to show country- and genderspecific results. Since working overtime is connected both with coronary health, job strain, and occupational class [37,38], it was initially adjusted for. However, it did not influence the associations between job strain and angina pectoris symptoms and was excluded from the final models.

Additionally, interactions between the main exposure (job strain), gender and cohort were examined within the pooled data. All the analyses were conducted using an SAS statistical program, version 8.2.

\section{RESULTS}

Angina pectoris symptoms were reported by 5\% $(\mathrm{n}=52)$ of women and 3\% $(\mathrm{n}=88)$ of men in the Whitehall II cohort, and by $6 \%(n=354)$ of women and $4 \%(n=48)$ of men in the Helsinki Health Study cohort (Table 1). Older men reported angina pectoris symptoms more often than their younger counterparts, while among women age differences were absent. 
Table 1. Basic characteristics of participants of the British Whitehall II study (19971999) cohort and the Finnish Helsinki Health Study (2000-2002) cohort, self-reported angina pectoris symptoms, job strain, and behavioral risk factors

\begin{tabular}{|c|c|c|c|c|c|c|c|c|}
\hline & \multicolumn{4}{|c|}{ London $(n=4551)$} & \multicolumn{4}{|c|}{ Helsinki $(n=7605)$} \\
\hline & \multicolumn{2}{|c|}{ Women } & \multicolumn{2}{|c|}{ Men } & \multicolumn{2}{|c|}{ Women } & \multicolumn{2}{|c|}{ Men } \\
\hline & $\mathbf{N}$ & $\%$ & $\mathbf{N}$ & $\%$ & $\mathbf{N}$ & $\%$ & $\mathbf{N}$ & $\%$ \\
\hline Angina pectoris symptoms & 52 & 5 & 88 & 3 & 354 & 6 & 48 & 4 \\
\hline Age (Mean, yrs.) & 1228 & 53 & 3323 & 52 & 6296 & 49 & 1309 & 50 \\
\hline \multicolumn{9}{|l|}{ Job strain } \\
\hline Low job strain & 291 & 28 & 963 & 33 & 1754 & 28 & 315 & 24 \\
\hline Active work & 239 & 23 & 728 & 25 & 1471 & 24 & 338 & 26 \\
\hline Passive work & 383 & 36 & 898 & 30 & 1691 & 27 & 335 & 26 \\
\hline High job strain & 139 & 13 & 358 & 12 & 1282 & 21 & 305 & 24 \\
\hline \multicolumn{9}{|l|}{ Socioeconomic status } \\
\hline Managers/ administrative & 301 & 25 & 1711 & 52 & 449 & 7 & 296 & 23 \\
\hline Professional/ semi-prof./ executive & 558 & 46 & 1417 & 43 & 2743 & 45 & 796 & 63 \\
\hline Routine non-manual/ clerical/ support & 363 & 30 & 181 & 5 & 2968 & 48 & 180 & 14 \\
\hline Current smoking ${ }^{*}$ & 159 & 13 & 524 & 16 & 1316 & 21 & 321 & 25 \\
\hline Heavy drinking $\dagger$ & 146 & 12 & 376 & 11 & 391 & 6 & 91 & 7 \\
\hline Physical inactivity & 249 & 20 & 771 & 23 & 1063 & 17 & 220 & 17 \\
\hline Unhealthy food habits & 114 & 9 & 355 & 11 & 625 & 10 & 281 & 21 \\
\hline Obese (BMI 30 or more) & 177 & 14 & 320 & 10 & 842 & 13 & 173 & 13 \\
\hline
\end{tabular}

* Smoking: Current smoker of cigarettes, cigars, or pipe

$\nmid$ Heavy drinking: Alcohol consumption over 280grams/wk for men and over 140 grams/wk for women

$\ddagger$ Physical inactivity: lowest active quintile

\$Unhealthy food habits: no item of three healthy items, i.e., not eating fresh vegetables or fruit at least twice a day, not choosing wholegrain bread, and not drinking low-fat milk 
High job strain was associated with angina pectoris symptoms among men in London and women in Helsinki in the age-adjusted models (Table 2). Adjusting for occupational class slightly attenuated these associations, but behavioral risk factors and obesity had negligible effects. Similar patterns were found for passive work among women but in Helsinki only.

Analyses stratified by gender and with cohort as a covariate produced similar results. High job strain remained associated with angina pectoris symptoms among all men (OR 1.90; CI 95\% 1.13-3.20) and women (OR 1.73; CI 95\% 1.27-2.37). Women reporting active or passive work also had more angina pectoris symptoms as compared to their low job strain counterparts, whereas among men corresponding associations were not observed. Finally, adjusting for both cohort and gender also produced a similar association between angina pectoris symptoms and high job strain (OR 1.70; CI 95\% 1.31-2.22). Women reported more angina pectoris symptoms than men (OR 1.53; CI 95\% 1.19-1.98), and there was both an age and a socio-economic gradient in symptom reporting. None of these associations depended on age, occupational class, or behavioral risk factors. However, the association between job strain and angina pectoris symptoms disappeared in London when the genders were pooled together. In Helsinki, corresponding interaction between job strain and gender was not observed. Interactions between job strain and cohort were not found.

Analyses with pooled data were stratified by occupational class as well. Those with high job strain were more likely to report angina pectoris symptoms across all occupational classes. Finally, we also examined separate effects of the two dimensions of the job strain model. High job demands (OR 1.44 CI 95\% 1.15-1.80) and low job control (OR 1.34 CI 95\% 1.05-1.70) were associated with angina pectoris symptoms only among women in Helsinki adjusting for age and occupational class. 
The point estimates were, however, of similar magnitude also among men in Helsinki and London (data not shown). 
Table 2. Angina pectoris symptoms and job strain among white-collar employees of the British Whitehall II study (1997-1999) cohort and the Finnish Helsinki Health Study (2000-2002) cohort

\begin{tabular}{|c|c|c|c|c|c|c|c|c|c|c|c|c|c|c|c|c|c|}
\hline & \multicolumn{9}{|c|}{ Women $(n=1038$ in Britain and $n=5944$ in Finland $)$} & \multicolumn{8}{|c|}{$\operatorname{Men}(n=2914$ in Britain and $n=1238$ in Finland) } \\
\hline & \multicolumn{3}{|c|}{ Model $1^{*}$} & \multicolumn{3}{|c|}{ Model $2^{\top}$} & \multicolumn{3}{|c|}{ Model $3^{+}$} & \multicolumn{3}{|c|}{ Model $1^{*}$} & \multicolumn{3}{|c|}{ Model $2^{\top}$} & \multicolumn{2}{|c|}{ Model $3^{+}$} \\
\hline & OR & CI & $5 \%$ & OR & CI 9 & $5 \%$ & OR & CI 9 & $5 \%$ & OR & CI 9 & $5 \%$ & OR & $\mathrm{CIO}$ & $95 \%$ & OR & CI $95 \%$ \\
\hline \multicolumn{18}{|l|}{ BRITAIN } \\
\hline \multicolumn{18}{|l|}{ Job strain } \\
\hline Low job strain & 1 & & & 1 & & & 1 & & & 1 & & & 1 & & & 1 & \\
\hline Active work & 1.582 & 0.722 & 3.464 & 1.948 & 0.870 & 4.360 & 2.017 & 0.898 & 4.534 & 0.915 & 0.473 & 1.770 & 0.971 & 0.499 & 1.888 & 0.971 & $0.498 \quad 1.892$ \\
\hline Passive work & 1.358 & 0.656 & 2.811 & 1.151 & 0.533 & 2.485 & 1.201 & 0.551 & 2.617 & 1.147 & 0.642 & 2.050 & 0.989 & 0.537 & 1.820 & 1.019 & $0.551 \quad 1.883$ \\
\hline High job strain & 0.520 & 0.144 & 1.873 & 0.449 & 0.124 & 1.635 & 0.476 & 0.130 & 1.738 & 2.254 & 1.182 & 4.298 & 2.066 & 1.074 & 3.976 & 2.077 & $1.073 \quad 4.021$ \\
\hline
\end{tabular}

\section{FINLAND}

\section{Job strain}

Low job strain

$\begin{array}{lllllllllll}\text { Active work } & 1.369 & 0.974 & 1.924 & 1.539 & 1.089 & 2.176 & 1.533 & 1.083 & 2.170 & 0.827\end{array}$

$\begin{array}{llllllllllll}\text { Passive work } & 1.679 & 1.222 & 2.308 & 1.404 & 1.013 & 1.947 & 1.409 & 1.015 & 1.958 & 0.794\end{array}$

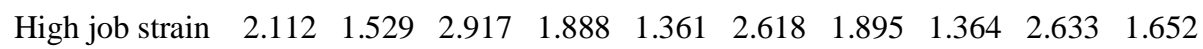

$\begin{array}{lllll}1 & 1\end{array}$

$\begin{array}{llllllll}0.338 & 2.024 & 0.824 & 0.335 & 2.026 & 0.861 & 0.344 & 2.156\end{array}$

$\begin{array}{lllllllll}0.333 & 1.893 & 0.800 & 0.333 & 1.926 & 0.793 & 0.324 & 1.944\end{array}$

$\begin{array}{llllllll}0.722 & 3.780 & 1.680 & 0.728 & 3.877 & 1.605 & 0.677 & 3.806\end{array}$

\section{* Model 1 Age-adjusted}

- Model 2 Age and occupational class adjusted for

= Model 3 Age and occupational class, and behavioral risk factors ${ }^{\text {? }}$ mutually adjusted for

Smoking, heavy drinking, physical inactivity, adverse food habits, obesity 


\section{DISCUSSION}

\section{Main findings}

This study sought to examine associations of job strain with angina pectoris symptoms. In this study, as previously [1], women reported more symptoms than men. While evidence for the associations between job strain and angina pectoris symptoms was received, this evidence was, however, inconsistent by cohort and gender. Clear associations were observed between angina pectoris symptoms and high job strain among women in Helsinki and men in London, but not among men in Helsinki and women in London. A low number of those with angina pectoris symptoms and high job strain contributes to random variation and leads to lack of statistical power. However, interaction analyses suggested that the associations between job strain and angina pectoris symptoms are similar between the cohorts. The non-existent findings among men in Helsinki and women in London remain, nevertheless, an open question that needs further corroboration.

\section{Previous studies}

This was the first international comparison between job strain and angina pectoris symptoms. A comparative study followed participants in four European countries and showed a clear association between job strain, acute coronary events, and coronary deaths.[39] As angina pectoris symptoms have been linked with clinical cardiovascular outcomes [40-42] and with cardiovascular and all-cause mortality [2,43-45], our results are in accordance with this evidence. Our findings are also in line with a Danish study, where job strain was associated with angina pectoris symptoms based on Rose Questionnaire among middle-aged urban women and men in Denmark.[46] Furthermore, adjusting for coronary risk factors and occupational social class did not explain the association in either our or the Danish study. In a British study among employed men aged 20-64 [8], job strain was related to angina pectoris 
symptoms assessed by Rose questionnaire. These associations were also independent of other coronary risk factors.

Job strain was found to be associated with angina pectoris symptoms in a previous study among the participants of the Whitehall II study as well, but these results combined genders.[47] Additionally, increase in effort-reward imbalance, over time was related to increased risk of angina pectoris symptoms among men but not among women.[48] In our previous study on angina pectoris symptoms among women in Helsinki, manual workers were included, and low job control as a dimension of high strain job was found to have a strong association with angina pectoris symptoms.[32] In a study among women and men from the Whitehall II cohort low job control was also a risk factor for incident coronary heart disease measured by Rose questionnaire, severe pain across the chest, and diagnosed ischemic heart disease.[13]

Finally, although working overtime did not contribute to the associations between job strain and angina pectoris symptoms, working hours, nevertheless, have previously been connected with cardiovascular and other health outcomes.[37,49-51] The effects of working overtime on the incidence and persistence of angina pectoris symptoms warrant thus further studies taking into account job strain and other working conditions.

\section{Study strengths and weaknesses}

A main strength of the present study is that recent and comparable data were available. Previous studies have mostly included only men and focused on one workplace or a national context only. Thus, our current emphasis on both women and men, and having data from two different national contexts are major strengths of this study. As women have been less often studied than men in occupational health research [52], this highlights the need to further focus on women and to elucidate understanding on the differences between women and men. In particular with respect 
to the present outcome, it is important to examine women and men separately, since the female dominance in symptom prevalence has remained over time and across cultures.[53] Additionally, the predictive power of angina pectoris symptoms for coronary endpoints is different among women and men.[34]

As a further strength, adverse health behaviors and obesity could be taken into account in the analyses providing evidence about their effects on the associations of job strain with angina pectoris symptoms. Identical items in their wording and content were used, which enabled accurate comparisons between the two cohorts.

Generalization of the results is also improved when findings can be drawn from two populations instead of only one.

Non-response analyses in the Helsinki cohort show that the data are broadly representative of the target population.[54] In the Whitehall II cohort, previous analysis about socio-economic position and common mental disorders comparing data from earlier phases with the phase 5 suggest that selective loss to follow-up or attrition are unlikely to distort the findings.[36] However, since phase 5 of the Whitehall II study was conducted 10-12 years after baseline, some civil servants with job strain could have been lost to follow-up.

The studied data comprised validated, widely-used measures concerning both angina pectoris symptoms $[4,30,34,35,42]$ and job strain. $[5,14]$ Due to the crosssectional design causal relationships between angina pectoris symptoms and job strain cannot be confirmed. Accordingly, psychosocial work problems may also be a consequence of chest pain.[55]

A limitation is that both the information about outcome and independent variables were based on self-reports collected simultaneously. Thus, those who report high job strain may also be disposed to report angina pectoris symptoms. Such a reporting bias has been speculated earlier.[20,56] However, a general disposition of reporting symptoms has not been found to distort the examination of angina pectoris 
symptoms.[13,27] As a further critique, the angina pectoris symptoms have been suggested to reflect psychological, psychosocial, or somatic symptoms instead of clinical angina.[27] While on one hand self-reports warrant cautious interpretations of the results, on the other hand symptoms can only be assessed using self-reported information.

Validation analyses using register data available for the Helsinki cohort suggest that the reported angina pectoris symptoms bear clinical significance and are associated with nitrate use, special reimbursements for coronary heart disease, and hospital care (Lallukka T et al. 2009, unpublished, data not shown). Register-based clinical angina was defined following previous definitions.[3]

Finally, only a single report on angina pectoris symptoms was examined. These questionnaire data reflect current symptoms, but a considerable variability over time in symptoms exists.[57] Persistent symptoms are related to a more severe disease, but also single reports on angina pectoris symptoms have proven valid and shown moderate associations with coronary heart disease and its risk factors.[42]

\section{CONCLUSIONS}

High job strain was related to angina pectoris symptoms in women from Helsinki and men from London, but not in men from Helsinki and women from London. The found associations could not be explained by socio-economic position, adverse behaviors or obesity. Thus this study provided partial evidence on the association between job strain and coronary health across national contexts. Due to inconsistent results further work is warranted. 


\section{ACKNOWLEDGEMENTS}

The Helsinki Health Study is supported by Academy of Finland (\#205588, (\#70631, \#48600, \#210435) and the Finnish Work Environment Fund. The Whitehall II study has been supported by grants from the Medical Research Council; British Heart Foundation; Health and Safety Executive; Department of Health; National Heart Lung and Blood Institute (HL36310), US, NIH: National Institute on Aging (AG13196), US, NIH; Agency for Health Care Policy Research (HS06516); and the

John D and Catherine T MacArthur Foundation Research Networks on Successful Midlife Development and Socio-economic Status and Health. MM is supported by an MRC Research Professorship. We thank all members of the Helsinki Health Study and the Whitehall II Study groups.

\section{WHAT THIS PAPER ADDS}

\section{What is already known on this subject?}

Job strain has been linked with cardio-vascular morbidity. However, associations between job strain and angina pectoris symptoms are poorly known and international comparisons are fully lacking.

\section{What does this study add?}

This study showed that job strain is associated with angina pectoris symptoms even after occupational social class, health behaviors, and obesity have been accounted for. However, the associations are inconsistent between cohorts and genders. This highlights a need for further scrutiny on the causal effects of job strain to angina pectoris symptoms across different cultural settings and employment sectors. 


\section{REFERENCES}

(1) Zaher C, Goldberg GA, Kadlubek P. Estimating angina prevalence in a managed care population. Am J Manag Care 2004(11 Suppl):S339-46.

(2) Hemingway H, Shipley M, Britton A, et al. Prognosis of angina with and without a diagnosis: 11 year follow up in the Whitehall II prospective cohort study. BMJ 2003 Oct 18;327:895-899.

(3) Hemingway H, McCallum A, Shipley M, et al. Incidence and prognostic implications of stable angina pectoris among women and men. JAMA 2006;295:14041411.

(4) Cosin J, Asin E, Marrugat J, et al. Prevalence of angina pectoris in Spain. PANES Study group. Eur J Epidemiol 1999;15:323-330.

(5) Karasek RA. Job demands, job decision latitude, and mental strain: implications for job redesign. Adm Sci $Q$ 1979;24:285-308.

(6) Belkic KL, Landsbergis PA, Schnall PL, et al. Is job strain a major source of cardiovascular disease risk? Scand J Work Environ Health 2004;30:85-128.

(7) Bosma H, Van Jaarsveld CH, Tuinstra J, et al. Low control beliefs, classical coronary risk factors, and socio-economic differences in heart disease in older persons. Soc Sci Med 2005;60:737-745.

(8) Sacker A, Bartley MJ, Frith D, et al. The relationship between job strain and coronary heart disease: evidence from an English sample of the working male population. Psychol Med 2001;31:279-290.

(9) Peter R, Siegrist J. Psychosocial work environment and the risk of coronary heart disease. Int Arch Occup Environ Health 2000;73 Suppl:S41-5.

(10) Yoshimasu K, Liu Y, Kodama H, et al. Job strain, type A behavior pattern, and the prevalence of coronary atherosclerosis in Japanese working men. J Psychosom Res 2000;49:77-83.

(11) Hemingway H, Marmot M. Psychosocial factors in the aetiology and prognosis of coronary heart disease: systematic review of prospective cohort studies. $\mathrm{Br} \mathrm{Med} \mathrm{J}$ 1999;318:1460-1467.

(12) Bosma H, Peter R, Siegrist J, et al. Two alternative job stress models and the risk of coronary heart disease. Am J Public Health 1998;88:68-74.

(13) Bosma H, Marmot MG, Hemingway H, et al. Low job control and risk of coronary heart disease in Whitehall II (prospective cohort) study. $\mathrm{Br} \mathrm{Med} J$ 1997;314:558-565. 
(14) Karasek R, Baker D, Marxer F, et al. Job decision latitude, job demands, and cardio-vascular disease: a prospective study of Swedish men. Am J Public Health 1981;71:694-705.

(15) Brunner EJ, Kivimäki M, Siegrist J, et al. Is the effect of work stress on cardiovascular mortality confounded by socioeconomic factors in the Valmet study? $J$ Epidemiol Community Health 2004;58:1019-1020.

(16) Kivimäki M, Leino-Arjas P, Luukkonen R, et al. Work stress and risk of cardiovascular mortality: prospective cohort study of industrial employees. $B M J$ 2002;325:857-861.

(17) Virtanen SV, Notkola V. Socioeconomic inequalities in cardiovascular mortality and the role of work: a register study of Finnish men. Int J Epidemiol 2002;31:614621.

(18) Aboa-Eboulé C, Brisson C, Maunsell E, et al. Job strain and risk of acute recurrent coronary heart disease events. JAMA 2007;298:1652-1660.

(19) Reed DM, LaCroix AZ, Karasek RA, et al. Occupational strain and the incidence of coronary heart disease. Am J Epidemiol 1989;129:495-502.

(20) Nielsen NR, Kristensen TS, Prescott E, et al. Perceived Stress and Risk of Ischemic Heart Disease: Causation or Bias? Epidemiology 2006;17:391-397.

(21) Everson-Rose SA, Lewis TT. Psychosocial factors and cardiovascular diseases. Annu Rev Public Health 2005;26:469-500.

(22) Lallukka T, Lahelma E, Rahkonen O, et al. Associations of job strain and working overtime with adverse health behaviors and obesity: Evidence from the Whitehall II Study, Helsinki Health Study, and the Japanese Civil Servants Study. Soc Sci Med 2008;66:1681-1698.

(23) Siegrist J, Rödel A. Work stress and health risk behavior. Scand J Work Environ Health 2006;32:473-481.

(24) Wege N, Dragano N, Erbel R, et al. When does work stress hurt? Testing the interaction with socioeconomic position in the Heinz Nixdorf Recall Study. $J$ Epidemiol Community Health 2008;62:338-341.

(25) Ezzati M, Henley SJ, Thun MJ, et al. Role of smoking in global and regional cardiovascular mortality. Circulation 2005;112:489-497.

(26) Hu G, Tuomilehto J, Silventoinen K, et al. The effects of physical activity and body mass index on cardiovascular, cancer and all-cause mortality among 47212 middle-aged Finnish men and women. Int J Obes 2005;29:894-902. 
(27) Nicholson A, White I, Macfarlane P, et al. Rose questionnaire angina in younger men and women: gender differences in the relationship to cardiovascular risk factors and other reported symptoms. J Clin Epidemiol 1999;52:337-346.

(28) Marmot M, Brunner E. Cohort Profile: the Whitehall II study. Int J Epidemiol 2005;34:251-256.

(29) Lahelma E, Martikainen P, Rahkonen O, et al. Occupational class inequalities across key domains of health: Results from the Helsinki Health Study. Eur J Public Health 2005;15:504-510.

(30) Rose GA. Ischemic heart disease. Chest pain questionnaire. Milbank Mem Fund $Q$ 1965;43:32-39.

(31) Rose GA, Blackburn H, Gillum RF, et al. Cardiovascular survey methods. Geneva: WHO; 1982.

(32) Lallukka T, Martikainen P, Reunanen A, et al. Associations between working conditions and angina pectoris symptoms among employed women. Psychosom Med 2006;68:348-354.

(33) Visscher TL, Viet AL, Kroesbergen IH, et al. Underreporting of BMI in adults and its effect on obesity prevalence estimations in the period 1998 to 2001. Obesity 2006;14:2054-2063.

(34) Garber CE, Carleton RA, Heller GV. Comparison of "Rose Questionnaire Angina" to exercise thallium scintigraphy: different findings in males and females. $J$ Clin Epidemiol 1992;45:715-720.

(35) Harris RB, Weissfeld LA. Gender differences in the reliability of reporting symptoms of angina pectoris. J Clin Epidemiol 1991;44:1071-1078.

(36) Laaksonen E, Martikainen P, Lahelma E, et al. Socioeconomic circumstances and common mental disorders among Finnish and British public sector employees: evidence from the Helsinki Health Study and the Whitehall II Study. Int J Epidemiol 2007;36:776-786.

(37) Spurgeon A, Harrington JM, Cooper CL. Health and safety problems associated with long working hours: a review of the current position. Occup Environ Med 1997;54:367-375.

(38) Grosch JW, Caruso CC, Rosa RR, et al. Long hours of work in the U.S.: associations with demographic and organizational characteristics, psychosocial working conditions, and health. Am J Ind Med 2006;49:943-952.

(39) Kornitzer M, deSmet P, Sans S, et al. Job stress and major coronary events: results from the Job Stress, Absenteeism and Coronary Heart Disease in Europe study. Eur J Cardiovasc Prev Rehabil 2006;13:695-704. 
(40) Oei HH, Vliegenthart R, Deckers JW, et al. The association of Rose questionnaire angina pectoris and coronary calcification in a general population: the Rotterdam Coronary Calcification Study. Ann Epidemiol 2004;14:431-436.

(41) Wilcosky T, Harris R, Weissfeld L. The prevalence and correlates of Rose Questionnaire angina among women and men in the Lipid Research Clinics Program Prevalence Study population. Am J Epidemiol 1987;125:400-409.

(42) Sorlie PD, Cooper L, Schreiner PJ, et al. Repeatability and validity of the Rose questionnaire for angina pectoris in the Atherosclerosis Risk in Communities Study. $J$ Clin Epidemiol 1996;49:719-725.

(43) Feinleib M, Lambert PM, Zeiner-Henriksen T, et al. The British-Norwegian migrant study--analysis of parameters of mortality differentials associated with angina. Biometrics 1982;38 Suppl:55-74.

(44) Bulpitt CJ, Shipley MJ, Demirovic J, et al. Predicting death from coronary heart disease using a questionnaire. Int J Epidemiol 1990;19:899-904.

(45) Owen-Smith V, Hannaford PC, Elliott AM. Increased mortality among women with Rose angina who have not presented with ischaemic heart disease. Br J Gen Pract 2003;53:784-789.

(46) Netterstrøm B, Kristensen TS, Moller L, et al. Angina pectoris, job strain, and social status: a cross-sectional study of employed urban citizens. Int J Behav Med 1998;5:312-322.

(47) Head J, Martikainen P, Kumari M, et al. Work Environment, Alcohol Consumption and Ill-Health: The Whitehall II Study. 2002;422:1-64.

(48) Chandola T, Siegrist J, Marmot M. Do changes in effort-reward imbalance at work contribute to an explanation of the social gradient in angina? Occup Environ Med 2005;62:223-230.

(49) Caruso CC, Hitchcock EM, Dick RB, et al. Overtime and Extended Work Shifts: Recent Findings on Illnesses, Injuries and Health Behaviors. 2004;2004-143:137.

(50) Shields M. Long working hours and health. Health Reports 1999;11:33-48.

(51) Virtanen M, Singh-Manoux A, Ferrie JE, et al. Long working hours and cognitive function: the Whitehall II Study. Am J Epidemiol 2009;169:596-605.

(52) Niedhammer I, Saurel-Cubizolles MJ, Piciotti M, et al. How is sex considered in recent epidemiological publications on occupational risks? Occup Environ Med 2000;57:521-527. 
(53) Hemingway H, Langenberg C, Damant J, et al. Prevalence of angina in women versus men: a systematic review and meta-analysis of international variations across 31 countries. Circulation 2008;117:1526-1536.

(54) Laaksonen M, Aittomäki A, Lallukka T, et al. Register-based study among employees showed small nonparticipation bias in health surveys and check-ups. J Clin Epidemiol 2008;61:900-906.

(55) Zachariae R, Melchiorsen H, Frobert O, et al. Experimental pain and psychologic status of patients with chest pain with normal coronary arteries or ischemic heart disease. Am Heart J 2001;142:63-71.

(56) Macleod J, Davey Smith G, Heslop P, et al. Psychological stress and cardiovascular disease: empirical demonstration of bias in a prospective observational study of Scottish men. BMJ 2002;324:1247-1251.

(57) Lampe FC, Whincup PH, Shaper AG, et al. Variability of angina symptoms and the risk of major ischemic heart disease events. Am J Epidemiol 2001;153:1173-1182. 